\title{
Occupational Noise Exposure in Small Scale Hand Tools Manufacturing (Forging) Industry (SSI) in Northern India
}

\author{
Lakhwinder Pal SINGH ${ }^{*}$, Arvind BHARDWAJ ${ }^{2}$, KK DEEPAK ${ }^{3}$ and Raman BEDI ${ }^{4}$ \\ ${ }^{1} \mathrm{PhD}$ Scholar \& Faculty in Department of Industrial \& Production Engineering, Dr B R Ambedkar National \\ Institute of Technology, Jalandhar, Punjab 144011, India \\ ${ }^{2}$ Department of Industrial \& Production Engineering, Dr B R Ambedkar National Institute of Technology, \\ Jalandhar, Punjab 144011, India \\ ${ }^{3}$ Department of Physiology, AIIMS New Delhi, India \\ ${ }^{4}$ Department of Mechanical Engineering, Dr B R Ambedkar National Institute of Technology, Jalandhar, Punjab \\ 144011, India
}

Received August 15, 2008 and accepted February 13, 2009

\begin{abstract}
Occupational noise has been recognized as hazardous for the human beings. A high noise level in forging shops is considered to lower the labour productivity and cause illness however occupational noise is being accepted as an integral part of the job. The present study has been carried out in $\mathbf{5}$ small scale hand tool forging units (SSI) of different sizes in Northern India in Punjab. Noise levels at various sections were measured. OSHA norms for hearing conservation has been incorporated which includes an exchange rate of $5 \mathrm{~dB}(\mathrm{~A})$, criterion level at $90 \mathrm{~dB}(\mathrm{~A})$, criterion time of $8 \mathrm{~h}$, threshold level=80 dB (A), upper limit=140 dB (A) and with F/S response rate. Equivalent sound pressure level $\left(L_{e q}\right)$ has been measured in various sections of these plants. Noise at various sections like hammer section, cutting presses, punching, grinding and barrelling process was found to be $>90 \mathrm{~dB}(\mathrm{~A})$, which is greater than OSHA norms. A crosssectional study on the basis of questionnaire has been carried out. The results of which revealed that $68 \%$ of the workers are not wearing ear protective equipments out of these $50 \%$ were not provided with PPE by the company. About $95 \%$ of the workers were suffering speech interference though high noise annoyance was reported by only $20 \%$. It has been established that the maximum noise exposure is being taken by the workers as they are working more than $8 \mathrm{~h}$ a day for six days per week. More than $90 \%$ workers are working 12 to $24 \mathrm{~h}$ over time per week which lead to very high noise exposure i.e. 50 to $80 \%$ per week higher than exposure time/week in USA or European countries ${ }^{15,16}$.
\end{abstract}

Key words: Occupational health, Noise exposure in SSI, Hearing conservation

\section{Introduction}

Occupational noise exposure has been identified as very prominent hazards for drop forge hammer operators all over the world. A high noise level in forging shops is considered to lower the labour productivity and cause illness. The main sources of noise in these shops are: dropforging and free-forging hammers, eccentric forging

*To whom correspondence should be addressed. presses, oil fired furnaces, equipment for finishing the hot forged products (grinding process and barrelling process), work-station fans, and cooling the machinery, etc. The small scale companies are emphasising more on profit making through productivity enhancement. In developing countries like India beside the economical growth and technological changes, the companies are striving for increasing the sales turnover, thus the workers are more stressed for the productivity along with the additional burden of noise exposure. The small scale hand tool man- 


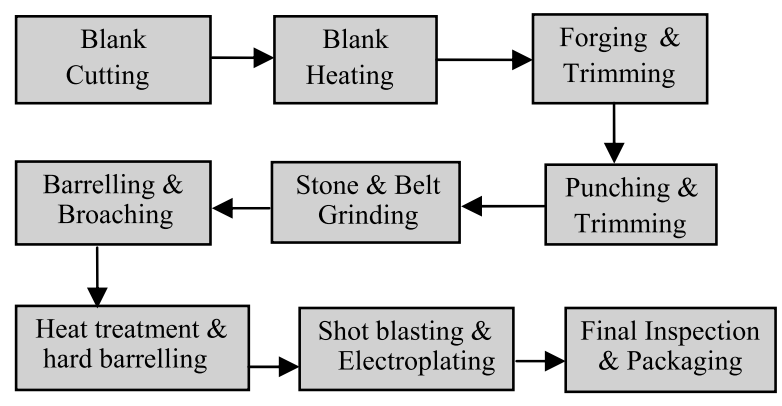

Fig. 1. Sequence of processes in a forging unit.

ufacturers of developing countries are lagging far behind in implementing hearing conservation, noise control programmes and occupational health \& safety programmes. Consequently the workers of hand tool forging units are exposed to the noise levels beyond the permissible limits. High noise exposure not only affects the communication among the workers but also lead to the other physiological, psychological and physical effects on the workers.

\section{Noise at Work Place}

In most of the small scale industries noise is perceived as a necessary evil. Since noise is an integral part of machinery in operation therefore it is being accepted "as a part of job". This attitude is persisting in a number of organizations especially among the management and workers of older industries where the traditional methods and machinery are still being used. As far as the SSI is concerned especially the iron \& steel units where heavy forging presses and drop hammers are main machinery assets, noise control efforts are still lagging behind. The sequence of operation of manufacturing the hand tools is shown in Fig. 1. The work place in most of the SSI is very congested due to lack of availability of space. The simultaneous running of blanking and punching presses, drop hammers, grinders and barrels etc. make the shop very noisy. The exposure to such a noisy environment is inevitable unless the proper hearing protection is taken. Most of the operations at different locations generates high noise $>90 \mathrm{~dB}$ (A) (Beyond the permissible limits). The impact produced by a hammer falling on a plate can generate an impulse whose peak level and duration can be varied $140-470 \mathrm{~ms}^{8}$. All continues, intermittent, and impulsive noise between the levels of 80 and $130 \mathrm{~dB}$ (A) must be included in the exposure assessment. Continuous noise is a noise whose maxima occurs more often than once per second. Thus impulsive noise is assumed to have peaks occurring less often than once a second, and is limited to peak sound pressure levels of $140 \mathrm{~dB}^{10)}$.

In this scenario the exposure to high noise is conse- quently followed by the noise induced hearing loss (NIHL), Physiological and Psychological effects. A number of studies have been carried out in last few decades regarding the assessment of occupational noise exposure and its auditory and non auditory health effects. In one study occupational noise exposure of truck drivers was found hazardous to hearing ${ }^{12)}$. Most of the studies have been carried out in developed countries, whereas the under developed countries like India are still lagging behind to explore the occupational health issues. One of the studies in India reports that workforce of two textile plants was at high risk of developing NIHL and other associated ailments ${ }^{15)}$. Indian factory act - 1948 lay down a limit of $90 \mathrm{~dB}(\mathrm{~A})$ for $8 \mathrm{~h} /$ day but the Indian working hours are 48/wk which leads to high noise exposure. Most of the workers are illiterate and semiliterate and they are not aware of the exposure norms and hazardous effects of noise ${ }^{16)}$.

\section{Subjects and Method}

The present study has been carried out in five SSI forging units located in Punjab state of northern India. These units are making hand tools like spanners, wrench, pliers, bench vice, hammers, axes etc. The number of employees in each unit is shown in Table 1. The number of workers in these units varies from 50 workers to 500 workers. A cross-sectional study has been conducted involving 451 randomly selected male workers. The age of workers ranges from $20 \mathrm{yr}$ to $55 \mathrm{yr}$ (Table 2). A comprehensive questionnaire was formulated to assess the subjective information. The questionnaire included age, noise exposure, working hours, use of protective measures, noise annoyance and awareness about NIHL (Appendix-A). The questionnaire was pretested and then was used to assess the information. The information was collected through personal interviews. Since the workers are mostly illiterate or less educated therefore statements of the questionnaire were translated in both local languages of the state i.e. Punjabi and Hindi. A five point scale was used to calculate the overall response for questionnaire parameters. The response choice weight ranges includes 4 (Always), 3 (Often), 2 (Sometime), 1 (Seldom) and 0 (Never). The other questions were having yes or no response i.e. 1 or 0 weights.

\section{Noise Measurement}

Workers were explained about the noise measurement procedure before the measurement was started at each section. The workers were allowed to observe the monitoring procedures and later on they were told about their exposures as recommended in ${ }^{11)}$. The noise exposure was 
Table 1. Number of workers interviewed in each section of each unit

\begin{tabular}{lrrrrrr}
\hline Forging Unit & 1 & 2 & 3 & 4 & 5 & Total \\
\hline Workers Interviewed in Sections & & & & & & \\
Blank cutting & 3 & 6 & 9 & 9 & 10 & 37 \\
Blank Heating & 2 & 6 & 6 & 6 & 10 & 30 \\
Drop Forging & 4 & 12 & 14 & 14 & 18 & 62 \\
Punching & 2 & 8 & 9 & 9 & 12 & 40 \\
Broaching/machining & 2 & 9 & 10 & 12 & 18 & 51 \\
Belt Grinding & 4 & 8 & 10 & 12 & 18 & 52 \\
Wheel Grinding & 4 & 8 & 10 & 12 & 18 & 52 \\
Duplex grinding & $\mathrm{NA}$ & 2 & 4 & 6 & 10 & 22 \\
Barrelling & $\mathrm{NA}$ & 2 & 2 & 3 & 6 & 13 \\
Straightening & $\mathrm{NA}$ & 3 & 2 & 3 & 6 & 14 \\
Gauging & 2 & 2 & 4 & 4 & 6 & 18 \\
Sizing & 1 & 2 & 4 & 4 & 6 & 17 \\
Nickel Plating/Painting & 2 & 4 & 6 & 8 & 12 & 32 \\
Gen Set & 1 & 2 & 2 & 2 & 4 & 11 \\
Workers interviewed & 27 & 74 & 92 & 104 & 154 & 451 \\
Total Employees & 50 & 150 & 350 & 450 & 500 & 1,500 \\
Percent Response rate $(\%)$ & 54 & 49 & 26 & 23 & 30 & 30 \\
\hline
\end{tabular}

Table 2. Distribution of age groups and years of exposure to noise under relevant processes

\begin{tabular}{lccccccc}
\hline Age & $20-24$ & $25-29$ & $30-34$ & $35-39$ & $40-44$ & $45-49$ & $50-55$ \\
Number of Subjects & $67(15 \%)$ & $90(20 \%)$ & $90(20 \%)$ & $67(15 \%)$ & $67(15 \%)$ & $45(10 \%)$ & $23(5 \%)$ \\
\hline Exposure (yr) & $1-2$ & $3-5$ & $6-10$ & $11-15$ & $16-20$ & $21-25$ & $>25$ \\
Number of Subjects & $45(10 \%)$ & $90(20 \%)$ & $112(25 \%)$ & $90(20 \%)$ & $59(13 \%)$ & $36(8 \%)$ & $18(4 \%)$ \\
\hline Age & $20-24$ & $25-29$ & $30-34$ & $35-39$ & $40-44$ & $45-49$ & $50-55$ \\
Number of Subjects & $67(15 \%)$ & $90(20 \%)$ & $90(20 \%)$ & $67(15 \%)$ & $67(15 \%)$ & $45(10 \%)$ & $23(5 \%)$ \\
\hline Exposure (yr) & $1-2$ & $3-5$ & $6-10$ & $11-15$ & $16-20$ & $21-25$ & $>25$ \\
Number of Subjects & $45(10 \%)$ & $90(20 \%)$ & $112(25 \%)$ & $90(20 \%)$ & $59(13 \%)$ & $36(8 \%)$ & $18(4 \%)$ \\
\hline
\end{tabular}

assessed by using a Quest sound level meter "ANSI 431997 (R2002) Type-1, model SOUNDPRO SE/DL". OSHA norms for hearing conservation were incorporated including an exchange rate of $5 \mathrm{~dB}(\mathrm{~A})$, criterion level at $90 \mathrm{~dB}(\mathrm{~A})$, criterion time of $8 \mathrm{~h}$, threshold level $=80 \mathrm{~dB}$ (A), upper limit $=140 \mathrm{~dB}(\mathrm{~A})$ and with $\mathrm{F} / \mathrm{S}$ response rate. The measurements in A-weighted sound pressure level were done. The measurements were recorded through data logging facility of the sound level meter and then transferred to computer for further analysis. The inbuilt quest make software was used for calculation and analysis. The measurement of noise was done in units with serial no. $1,3 \& 5$ (Table 1). The sound pressure level at different locations of each section among these units differed up to $\pm 0.5 \mathrm{~dB}$ (A). Since the machinery and layout of these units was almost of the same pattern i.e. congested type. In all the five units the process are carried out one adjacent to another. There is no isolation among different sections e.g. hammer section and other sections like punching, barrelling, and grinding etc. The workers are actually exposed to these noises since the workers have very less movement and they remain seated at one place during the working hours, except the movement of very few helpers within the same section. As a prevailing practice the workers are given $30 \mathrm{~min}$ lunch break and two tea breaks (5 min each) excluding the work time of $8-12 \mathrm{~h}$. Most of the work locations have an almost steady noise production except the drop forge hammers and punching/blanking presses. The sound pressure was recorded for $15 \mathrm{~min}$ each time on each work station and one long term recording for $4 \mathrm{~h}$ was done. There was hardly a difference of 0.5 to $1.0 \mathrm{~dB}$ (A) between long term recoding and short term recording. At each section sound pressure was recorded at least 4-5 times at different locations where the workers actually work or movement of the workers was most frequent. All the workers work at one place throughout the day excluding the helpers for material handling. There were 
1-2 helpers in section like hammer, grinding depending upon the size of the unit. The noise measurements were done in a circle of 1-2 feet radius from the ear of the workers. The sound pressure near the worker's head/ear and at 5 to 10 feet away from the head was differed by 0.5 to $1.0 \mathrm{~dB}(\mathrm{~A})$ at grinding section and 0.5 to $1.5 \mathrm{~dB}(\mathrm{~A})$ at barrel section and drop forge section. Equivalent sound pressure level has been measured Leq in various sections of these plants.

\section{Results and Discussion}

\section{Noise levels}

Results of the noise measurements reveal that overall noise level and exposure to noise in forging units under study ranged from 86.5 and $110 \mathrm{~dB}(\mathrm{~A}) \mathrm{L}_{\mathrm{eq}}$. The details of $\mathrm{L}_{\mathrm{eq}}, \mathrm{L}_{\min }, \mathrm{L}_{\max }$ and $\mathrm{L}_{\mathrm{pk}}$ values are shown in Table 3 . The daily exposure of workers in sections like blank cutting, forging, punching press, wheel and belt grinding, barrelling section, broaching, gauging and sizing etc. exceeds maximum exposure limit of $90 \mathrm{~dB}(\mathrm{~A})$ specified by OSHA and Indian factories act. The noise exposure

Table 3. Noise measurements at various sections of small scale hand tools manufacturing forging plants

\begin{tabular}{|c|c|c|c|c|c|c|c|c|c|}
\hline Blank Cutting & $\mathrm{L}_{\mathrm{eq}}$ (A) dB & $\mathrm{L}_{\min }(\mathrm{A}) \mathrm{dB}$ & $\mathrm{L}_{\max }(\mathrm{A}) \mathrm{dB}$ & $\mathrm{L}_{\mathrm{pk}}$ (A) dB & Belt Grinding & $\mathrm{L}_{\mathrm{eq}}(\mathrm{A}) \mathrm{dB}$ & $\mathrm{L}_{\min }(\mathrm{A}) \mathrm{dB}$ & $\mathrm{L}_{\max }(\mathrm{A}) \mathrm{dB}$ & $\mathrm{L}_{\mathrm{pk}}(\mathrm{A}) \mathrm{dB}$ \\
\hline Location -1 & 101.9 & 92.5 & 115.0 & 135.2 & Location -1 & 94.9 & 90.4 & 98.9 & 112.9 \\
\hline Location -2 & 101.2 & 92.9 & 116.1 & 135.4 & Location -2 & 94.5 & 90.2 & 98.4 & 112.5 \\
\hline Location -3 & 101.6 & 92.3 & 115.6 & 134.9 & Location -3 & 95.5 & 90.8 & 99.2 & 112.9 \\
\hline Location -4 & 102.4 & 92.8 & 115.9 & 135.1 & Location -4 & 94.9 & 90.6 & 99.2 & 112.6 \\
\hline Drop Forge & $\mathrm{L}_{\mathrm{eq}}(\mathrm{A}) \mathrm{dB}$ & $\mathrm{L}_{\min }(\mathrm{A}) \mathrm{dB}$ & $\mathrm{L}_{\max }(\mathrm{A}) \mathrm{dB}$ & $\mathrm{L}_{\mathrm{pk}}(\mathrm{A}) \mathrm{dB}$ & Barrelling & $\mathrm{L}_{\mathrm{eq}}(\mathrm{A}) \mathrm{dB}$ & $\mathrm{L}_{\min }(\mathrm{A}) \mathrm{dB}$ & $\mathrm{L}_{\max }(\mathrm{A}) \mathrm{dB}$ & $\mathrm{L}_{\mathrm{pk}}(\mathrm{A}) \mathrm{dB}$ \\
\hline Location -1 & 102.1 & 94.8 & 115.1 & 135.0 & Location -1 & 99.2 & 92.1 & 103.8 & 118.4 \\
\hline Location -2 & 101.7 & 95.5 & 110.9 & 129.8 & Location -2 & 101.9 & 94.7 & 113 & 134.6 \\
\hline Location -3 & 100.6 & 90.8 & 113.3 & 134.8 & Location -3 & 105.3 & 98.8 & 111 & 124.2 \\
\hline Location -4 & 101.2 & 94.0 & 116.0 & 125.2 & Location -4 & 110.2 & 98.0 & 115.0 & 129.2 \\
\hline Location -5 & 101.7 & 92.9 & 118.6 & 134.6 & Location -5 & 107.0 & 93.5 & 113.5 & 126.5 \\
\hline Location -6 & 101.2 & 82.4 & 115.7 & 134.8 & & & & & \\
\hline Location -7 & 103.8 & 92.2 & 118.6 & 140.9 & & & & & \\
\hline Punch Press & $\mathrm{L}_{\mathrm{eq}}(\mathrm{A}) \mathrm{dB}$ & $\mathrm{L}_{\min }(\mathrm{A}) \mathrm{dB}$ & $\mathrm{L}_{\max }(\mathrm{A}) \mathrm{dB}$ & $\mathrm{L}_{\mathrm{pk}}(\mathrm{A}) \mathrm{dB}$ & Straightening & $\mathrm{L}_{\mathrm{eq}}(\mathrm{A}) \mathrm{dB}$ & $\mathrm{L}_{\min }(\mathrm{A}) \mathrm{dB}$ & $\mathrm{L}_{\max }(\mathrm{A}) \mathrm{dB}$ & $\mathrm{L}_{\mathrm{pk}}(\mathrm{A}) \mathrm{dB}$ \\
\hline Location -1 & 98.9 & 93.5 & 111.2 & 126.3 & Location -1 & 96.5 & 87.2 & 106.4 & 128.5 \\
\hline Location -2 & 99.8 & 94.6 & 107.7 & 127.7 & Location -2 & 95.6 & 86.4 & 105.4 & 126.4 \\
\hline Location -3 & 101.1 & 95.1 & 109.9 & 127.2 & Location -3 & 94.6 & 86.4 & 104.4 & 127.5 \\
\hline Location -4 & 100.2 & 94.0 & 109.0 & 126.9 & Location -4 & 95.6 & 87.4 & 106.4 & 128.5 \\
\hline Location -5 & 101.2 & 95.0 & 109.9 & 126.2 & & & & & \\
\hline Broaching & $\mathrm{L}_{\mathrm{eq}}(\mathrm{A}) \mathrm{dB}$ & $\mathrm{L}_{\min }(\mathrm{A}) \mathrm{dB}$ & $\mathrm{L}_{\max }(\mathrm{A}) \mathrm{dB}$ & $\mathrm{L}_{\mathrm{pk}}(\mathrm{A}) \mathrm{dB}$ & Gauging-Sizing & $\mathrm{L}_{\mathrm{eq}}(\mathrm{A}) \mathrm{dB}$ & $\mathrm{L}_{\min }(\mathrm{A}) \mathrm{dB}$ & $\mathrm{L}_{\max }(\mathrm{A}) \mathrm{dB}$ & $\mathrm{L}_{\mathrm{pk}}(\mathrm{A}) \mathrm{dB}$ \\
\hline Location -1 & 101.9 & 94.7 & 113.6 & 134.6 & Location -1 & 93.3 & 88.1 & 104.0 & 120.1 \\
\hline Location -2 & 99.1 & 92.1 & 103.6 & 118.4 & Location -2 & 92.6 & 87.1 & 103.4 & 119.5 \\
\hline Location -3 & 96.1 & 92.4 & 98.2 & 112.9 & Location -3 & 93.1 & 87.9 & 103.8 & 121.0 \\
\hline Location -4 & 96.5 & 91.1 & 98.9 & 118.2 & Location -4 & 92.9 & 87.9 & 103.9 & 119.8 \\
\hline Wheel Grinding & $\mathrm{L}_{\mathrm{eq}}(\mathrm{A}) \mathrm{dB}$ & $\mathrm{L}_{\min }(\mathrm{A}) \mathrm{dB}$ & $\mathrm{L}_{\max }(\mathrm{A}) \mathrm{dB}$ & $\mathrm{L}_{\mathrm{pk}}(\mathrm{A}) \mathrm{dB}$ & Nickel Plating & $\mathrm{L}_{\mathrm{eq}}(\mathrm{A}) \mathrm{dB}$ & $\mathrm{L}_{\min }(\mathrm{A}) \mathrm{dB}$ & $\mathrm{L}_{\max }(\mathrm{A}) \mathrm{dB}$ & $\mathrm{L}_{\mathrm{pk}}(\mathrm{A}) \mathrm{dB}$ \\
\hline Location -1 & 96.1 & 92.4 & 98.2 & 112.9 & Location -1 & 88.0 & 82.8 & 106.2 & 121.3 \\
\hline Location -2 & 96.5 & 91.1 & 98.9 & 118.2 & Location -2 & 87.9 & 84.7 & 105.9 & 119.9 \\
\hline Location -3 & 94.6 & 90.2 & 98.9 & 113.0 & Location -3 & 88.1 & 83.8 & 106.1 & 120.7 \\
\hline \multirow[t]{2}{*}{ Location -4} & 95.6 & 91.2 & 98.4 & 114.0 & Location -4 & 87.9 & 84.5 & 105.7 & 119.6 \\
\hline & & & & & Location -5 & 86.5 & 82.4 & 103.2 & 118.8 \\
\hline Duplex Grinding & $\mathrm{L}_{\mathrm{eq}}(\mathrm{A}) \mathrm{dB}$ & $\mathrm{L}_{\min }(\mathrm{A}) \mathrm{dB}$ & $\mathrm{L}_{\max }(\mathrm{A}) \mathrm{dB}$ & $\mathrm{L}_{\mathrm{pk}}(\mathrm{A}) \mathrm{dB}$ & Gen Set & $\mathrm{L}_{\mathrm{eq}}(\mathrm{A}) \mathrm{dB}$ & $\mathrm{L}_{\min }(\mathrm{A}) \mathrm{dB}$ & $\mathrm{L}_{\max }(\mathrm{A}) \mathrm{dB}$ & $\mathrm{L}_{\mathrm{pk}}(\mathrm{A}) \mathrm{dB}$ \\
\hline Location -1 & 94.7 & 90.5 & 104.1 & 120.0 & Location -1 & 96.1 & 91.1 & 102.1 & 125.6 \\
\hline Location -2 & 93.8 & 89.8 & 99.4 & 115.3 & Location -2 & 96.5 & 90.8 & 102.0 & 124.5 \\
\hline Location -3 & 94.7 & 90.5 & 104.1 & 120.0 & Location -3 & 95.9 & 91.2 & 100.6 & 123.6 \\
\hline Location -4 & 93.8 & 89.8 & 99.4 & 115.3 & Location -4 & 96.8 & 91.4 & 102.3 & 125.5 \\
\hline
\end{tabular}


in other work areas like nickel plating, machine section, die section is recorded less than $90 \mathrm{~dB}(\mathrm{~A})$, but is quite higher than the limits used for assessment of noise for community noise ${ }^{15)}$. The direct application of OSHA norms in Indian SSI is not valid because most of the plants operated more than $8 \mathrm{~h} / \mathrm{d}$ and six d/wk i.e. exposure time is $48 \mathrm{~h} / \mathrm{wk}$. In the interview it was reported by most of the workers that they opt for 2 to $4 \mathrm{~h} / \mathrm{d}$ over time i.e. 12 to $24 \mathrm{~h} / \mathrm{wk}$ (Table 4). This fact was also established by the managers of the plants. Therefore the workers are under total exposure of 20 to 32 h (i.e. 50-80\%) per week higher than exposure time per week in USA or European countries ${ }^{14,15)}$. Chronic exposure to noise levels typical of many workplaces can cause risk of acute myocardial infarction death. Exposure to high intensity noise of $88-107 \mathrm{~dB}$ (A) $6-8 \mathrm{~h} / \mathrm{d}$ for long duration (10-15 yr) can cause biochemical changes which make the workers prone to cardiovascular pathology ${ }^{1,6}$.

\section{Subjective response to noise}

The subjective response was collected from 451 workers randomly selected from each of the five units (Table 1). The distribution of workers in each age group and experience group is shown in Table 2. The results of the questionnaire interviews revealed that $5 \%$ of the workers reported always annoyed, $15 \%$ often, $22 \%$ sometime, $20 \%$ workers were seldom annoyed and $38 \%$ never felt annoyed with high noise levels. The same could be attributed to the workers acceptance of noise as a part of their job, secondly the increasing adaptability with the increasing exposure to high noise levels. Noise annoyance was more among age group of 30-34 and exposure group of $5 \mathrm{yr}$ of work experience as compare to other groups (Table 5). The overall noise annoyance level on a five point scale was 1.29. Nevertheless the occupational noise annoyance combined with nightshift work, and work satisfaction can cause ill effects on blood pressure ${ }^{2)}$. As far as the head ache due to work place noise is concerned only $5 \%$ reported always and $10 \%$ with often report of head ache this was observed in newly employed workers which could be attributed to their adaptability to the environment and hearing threshold loss. The overall head ache level due to work place noise was 1.76 on a five point scale. In case of speech interference $30 \%$ of the workers reported high, $25 \%$ moderate, $25 \%$ workers reported low and $15 \%$ reported least speech interference

Table 4. Subjective response \%age (N) and level of each factor on 5 point scale (weight range 0-4) ratios of workers for various questions

\begin{tabular}{|c|c|c|c|c|c|c|}
\hline Response Choice & i) & ii) & iii) & iv) & v) & Level \\
\hline \multicolumn{7}{|l|}{ Question } \\
\hline 1) Noise annoyance & $5 \%(23)$ & $15 \%(67)$ & $22 \%(99)$ & $20 \%(90)$ & $38 \%(171)$ & 1.29 \\
\hline 2) Head ache due to noise & $5 \%(23)$ & $10 \%(45)$ & $50 \%(225)$ & $25 \%(113)$ & $10 \%(45)$ & 1.76 \\
\hline 3) Speech Interference & $30 \%(135)$ & $25 \%(113)$ & $15 \%(67)$ & $25 \%(113)$ & $5 \%(23)$ & 2.50 \\
\hline 4) Awareness of noise ill effects & $40 \%(180)$ & $60 \%(270)$ & NA & NA & NA & NA \\
\hline 5) Hearing disability & $65 \%(292)$ & $35 \%(158)$ & NA & NA & NA & NA \\
\hline 6) Awareness of benefits of PPE & $70 \%(315)$ & $30 \%(135)$ & NA & NA & NA & NA \\
\hline 7) Management enforces to wear PPE & $30 \%(135)$ & $70 \%(315)$ & NA & NA & NA & NA \\
\hline 8) Use of PPE by workers & $5 \%(23)$ & $7 \%(32)$ & $8 \%(36)$ & $12 \%(54)$ & $68 \%(306)$ & 0.70 \\
\hline 9) Cause of not/irregular using PPE & $30 \%(157)$ & $10 \%(45)$ & $20 \%(135)$ & $40 \%(113)$ & NA & NA \\
\hline 10) Working hours/day & $15 \%(67)$ & $85 \%(383)$ & NA & NA & NA & NA \\
\hline 11) Weekly overtime & $10 \%(38)$ & $15 \%(58)$ & $35 \%(134)$ & $40 \%(153)$ & NA & NA \\
\hline 12) Level of satisfaction with work environment & $30 \%(135)$ & $24 \%(108)$ & $26 \%(117)$ & $15 \%(67)$ & $5 \%(23)$ & 2.59 \\
\hline
\end{tabular}

For questions 1, 2, 3 \& 8 choice options are i) - Always, ii) - Often, iii) - Sometime, iv) - Seldom, v) - Never.

For questions 4, 5, $6 \& 7$ choice options are i) - Yes, ii) - No.

For questions $9,10,11 \& 12$ ref. Appendix-A.

Table 5. Distribution of noise annoyance w.r.t. age group and years of exposure

\begin{tabular}{lcccccccc}
\hline Age Range (yr) & $20-24$ & $25-29$ & $30-34$ & $35-39$ & $40-44$ & $45-49$ & $50-55$ & Total \\
$\begin{array}{l}\text { Noise Annoyance } \\
\text { Number of workers }\end{array}$ & $28(10 \%)$ & $70(25 \%)$ & $84(30 \%)$ & $62(22 \%)$ & $28(10 \%)$ & $6(2 \%)$ & $2(1 \%)$ & 280 \\
\hline Exposure (yr) & $1-2$ & $3-5$ & $6-10$ & $11-15$ & $16-20$ & $21-25$ & $>25$ & Total \\
$\begin{array}{l}\text { Noise annoyance } \\
\text { Number of workers }\end{array}$ & $42(15 \%)$ & $84(30 \%)$ & $70(25 \%)$ & $42(15 \%)$ & $28(10 \%)$ & $11(4 \%)$ & $3(1 \%)$ & 280 \\
\hline
\end{tabular}


due to high noise levels. The workers engaged in hammer section, punching/blanking, grinding, broaching and barrelling sections were the main sufferers of speech interference. The overall speech interference level on a five point scale was 2.5 , which is second highest among all parameters. As only $40 \%$ of the workers reported awareness about the hazardous effects of noise, this factor is very much related to the fact of high percentage (68\%) of workers almost not wearing PPE. Where as only 5\% workers reported always use, and rest of the workers reported some time, often and seldom use of PPE at work place. As observed at the time of survey these workers were mainly from forging section, grinding section, punching press, blank cutting, machining and barrelling sections. The overall level of use of PPE on a five point scale was 0.70 , which is the least observed parameters; the use of PPE is the most important and critical parameter but least preferred and prevailing. As far as the reasons for not using PPE were concerned $35 \%$ of these feel uncomfortable, 10 were not habitual of wearing the PPE, $30 \%$ due to their negligence and $25 \%$ were not getting PPE. High percent of hearing disability can be directly related to the high noise level, longer exposure time and also with the high ratio of workers not using PPE. As shown in (Table 4) 85\% worker are working more than $8 \mathrm{~h} / \mathrm{d}$, and $90 \%$ of these workers are doing $12-24 \mathrm{~h}$ over time/wk which lead to very high noise exposure i.e.
50 to $80 \%$ per week higher than exposure time/wk in USA or European countries ${ }^{15,16)}$. These long working hours and overtime are additional sufficient grounds for considering health hazardous in the work place ${ }^{20)}$. The workers usually wear ear plugs, turban and cotton as PPE as shown in (Fig. 2). It is very much clear that only $12 \%$ of workers are using ear plugs, $20 \%$ are wearing cotton $\&$ turban (inappropriate ear protection) and $68 \%$ are not using ear protection. This fact reveal that majority of the workers are directly exposed to high level of noise 92-110 dB(A) L $\mathrm{L}_{\text {eq }}$ without using PPE (Fig. 3). Chronic exposure to such kind of noise levels typical of many workplaces can cause risk of acute myocardial infarction death ${ }^{1)}$. A long exposure to noise over $85 \mathrm{~dB}(\mathrm{~A})$ might be a risk factor for high $\mathrm{BP}$, contributing to an increase in $\mathrm{BP}$ in the population and possibly inducing major

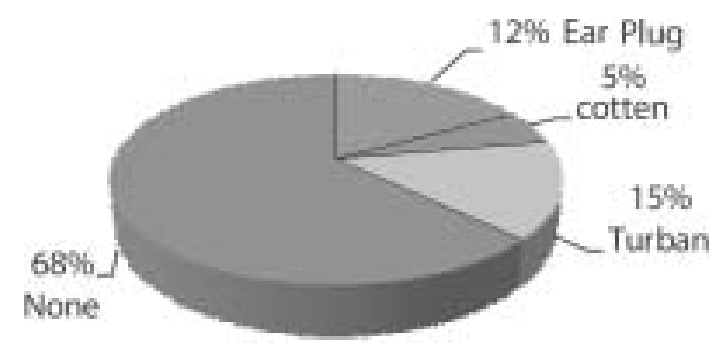

Fig. 2. Use of Ear Protection by the workers.

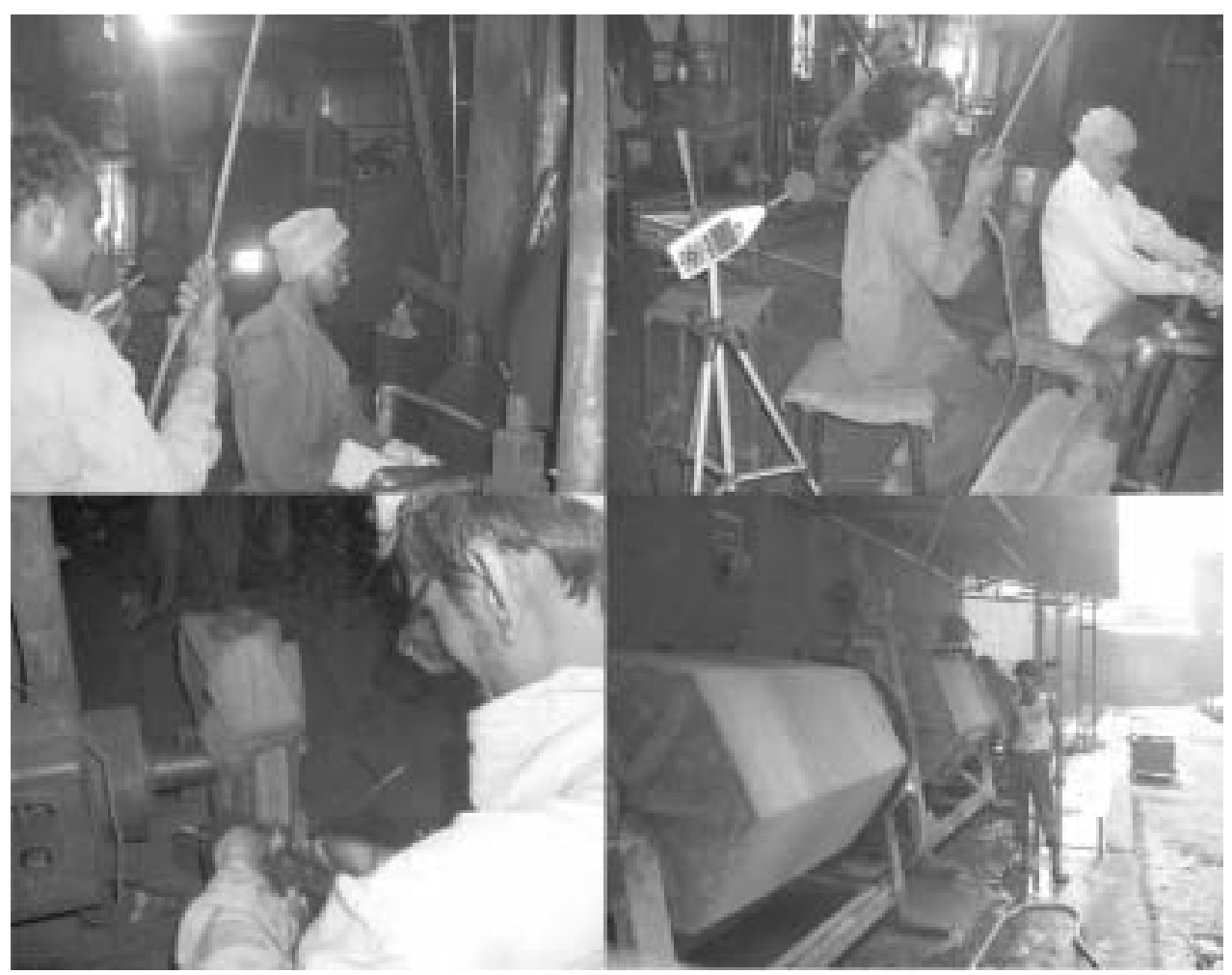

Fig. 3. Workers without proper PPE at forging, grinding and barrelling sections respectively. 
increases of $\mathrm{BP}$ among sensitive individuals ${ }^{3)}$. Noise exposure has been known to cause hearing loss for over a century, it is only recently that exposure limits have been legally adopted however; strict enforcement of current permissible exposure levels would not eliminate occupational hearing loss from industry ${ }^{4)}$. Such a higher exposure to impulsive and continuous noise can be responsible for NIHL and biochemical changes which may need further investigation. The NIHL can be seen in the form of PTS or TTS, since the forging workers those who are engaged in hammer section are also exposed to temperature and physical load therefore the TTS driven by noise exposure is enhanced by heat and workload $^{7)}$. The revision of occupational Indian Noise standard is recommended at par with International/ European standards ${ }^{5)}$. Hearing protection must be provided at no cost to employees and must be worn by all workers exposed to a TWA of $90 \mathrm{~dB}$ (A) and above. Exposure to high levels of impulse noise (despite the use of ear protectors) is more detrimental to hearing than are high levels of continuous noise (event continuous with slightly impulsive features). Impulse noise can produce permanent threshold shifts at certain frequencies after a clearly shorter duration of exposure than continuous noise ${ }^{13)}$. The whole discussion on the bases of results of measurements and subjective responses it is concluded that the workforce of SSI forging units is at a high risk of chronic effects of occupational noise. This may lead to auditory, physiological and psychological impairments of the SSI workforce which can be investigated in future scope. Further study can be extended with investigation of autonomic tone of the exposed workers. Therefore the future scope of the present study is very wide in the county. The authors recommends that exposure limit stipulated by OSHA of $90 \mathrm{~dB}$ (A) for $8 \mathrm{~h} / \mathrm{d}$ shall be followed with caution. It is also recommended to establish a hearing conservation programmes including the noise assessment, awareness among workers and audiometry.

\section{Conclusions}

The small scale industries of developing countries like India are still far behind in implementing occupational health and safety programmes. The present study was specifically focused on hand tools manufacturing (forging) plants the crux of the study can be enumerated as follows:

1. Majority of the workers are not wearing hearing protective equipments and suffer from NIHL. Main reasons were their negligence, feeling of un-comfortableness and are not provided by the management.

2. Mostly workers are illiterate or very less educated even under primary or middle and are not fully aware of the hazardous effects of noise.

3. Almost all the workers are highly exposed to high noise levels [ $>90 \mathrm{~dB}(\mathrm{~A})], 60$ to $72 \mathrm{~h} /$ wk without proper ear protection, which is very high as compared to OSHA norms.

4. There is a dire need to implement the noise working hours standard and hearing conservation programmes under ethical/legal control.

5. The SSI should be encouraged and facilitated to implement hearing conservation programmes under a good association with occupational health and environment professional.

6. The workers should be motivated to use PPE and educated for NIHL and other non auditory affects of noise exposure.

\section{Acknowledgement}

The authors acknowledge the co-operation and help extended by the management and the workers of small scale hand tool manufacturing units of the region for conducting personal interviews and measuring noise levels at each section very thoroughly.

\section{References}

1) Davies HW, Teschke K, Kennedy SM, Hodgson MR, Hertzman C, Demers PA (2005) Occupational exposure to noise and mortality from acute myocardial infarction. Epidemiology 16, 25-32.

2) Lercher P, Hortnagl J, Kofler WW (1993) Work noise annoyance and blood pressure: combined effects with stressful working conditions. Int Arch Occup Environ Health 65, 23-8.

3) Lang T, Fouriaud C, Jacquinet-Salord MC (1992) Length of occupational noise exposure and blood pressure. Int Arch Occup Environ Health 63, 369-72.

4) Hetu R (1994) The risk of hearing loss from exposure to noise. Groupe d'acoustique de l'université de Montréal, University of Montreal, Montreal.

5) Kisku GC, Bhargwa SK (2006) Assessment of noise level of a medium scale thermal power plant. Indian J Occup Environ Med 10, 133-9.

6) Rai RM, Singh AP, Upadhyay TN, Patil SKB, Nayar HS (1981) Biochemical effects of chronic exposure to noise in man. Int Arch Occup Environ Health 48, 331-7.

7) Chen C-J, Dai Y-T, Sun Y-M, Chang Y, Juang Y-J (2007) Evaluation of auditory fatigue in combined noise, heat and workload exposure. Ind Health 45, 527-34.

8) Tremolieres C, Hetu R (1980) A multi-parametric study of impact noise -induced TTS. J Acoust Soc Am 68, 1652-9.

9) Smeatham D, Wheeler PD (1998) On the performance of hearing protectors in impulsive Noise. Applied Acoustics 54, 165-81. 
10) OSHA's Noise Standard Defines Hazard Protection, Resource Guide 2000.

11) van den Heever DJ, Roets FJ (1996) Noise exposure of truck drivers: a comparative study. Am Ind Hyg Assoc J 57, 564-6.

12) Mäntysalo S, Vouri J (1984) Effects of impulse noise and continuous steady state noise on hearing. $\mathrm{Br} \mathrm{J}$ Ind Med 41, 122-32.

13) Khuranet AM, Al-Attar F (2000) Preliminary assessment of indoor industrial noise pollution in Kuwait. The Environmentalist 20, 319-24.

14) Bedi R (2006) Evaluation of occupational environment in two textile plants in northern India with specific reference to noise. Ind Health 44, 112-6.

15) Bedi R, Shukla DK, Sachdeva A (2004) Effects of Impact noise on humans - a case study of drop forge hammers. Proceeding of 7th Int. Symposium Transport Noise and Vibration, St. Petersburg, Russia.

16) IS: 7194-(1994) Indian standard, assessment of noise during work for hearing conservation purpose. (First revision) BIS India, New Delhi.

17) IS: 9989-(1981) Indian standard, assessment of noise with respect to community response, BIS India, New Delhi.

18) Occupational noise exposure Revised criteria (1998) US department of Health and Human Services, NIOSH, Cincinnati.

19) Occupational Noise Surveys, April-2007. worksafebc.com.

20) Dembe AE (2008) Ethical issues relating to the health effects of long working hours. J Bus Ethics 84 (Suppl 2), 195-208.

\section{Appendix-A}

\section{Questionnaire for Interview.}

Name Age Work Experience

1. Do you feel annoyed with high noise level at work place?

i) Always, ii) Often, iii) Sometime, iv) Seldom, v) Never

2. Do you have problem of head ache due to noise at work place?

i) Always, ii) Often, iii) Sometime, iv) Seldom, v) Never

3. Does noise causes speech interference?

i) Always, ii) Often, iii) Sometime, iv) Seldom, v) Never

4. Are you aware of hazardous effects of noise?
i)Yes
ii) No

5. Do you have hearing disability due to work noise?
i) Yes
ii) No

6. Do you know the benefits of using the protective equipments?
i)Yes
ii) No

7. Do management enforce you to wear the protective equipments?
i) Yes
ii) No

8. How much you use personal protective equipments (PPE) at work place?

\begin{tabular}{|c|l|l|l|l|l|}
\hline Level of use & \multirow{2}{*}{ i) Always } & ii) Often & iii) Sometime & iv) Seldom & v) Never \\
\cline { 1 - 5 } Type of PPE & & & & & \\
\hline Ear Plugs & & & & & \\
\hline Cotton & & & & & \\
\hline Safa/Turban & & & & & \\
\hline
\end{tabular}

9. If you do not use the protective equipments always, then specify the reason?

i) Feel uncomfortable, ii) Do not have habit, iii) Due to negligence, iv) Not provided by the company

10. What is working time/day?
i) 8 hours
ii) $>8$ hours

11. How much overtime/week you have?

i) 5-10 hours, ii) 11-15 hours, iii) 16-20 hours, iv) 21-24 hours

12. Rate your satisfaction with your work environment?

i) Highly, ii) Moderate, iii) Low, iv) Least, v) Not at all

(Signature of Worker) 